\title{
Uncertainty Management in Software Projects
}

\author{
Marcelo Luiz Monteiro Marinho ${ }^{1 *}$, Suzana Cândido de Barros Sampaio1, Telma Lúcia de \\ Andrade Lima², Hermano Perrelli de Moura ${ }^{3}$ \\ 1 Federal Rural University of Pernambuco (UFRPE), Statistics and Informatics Department (DEINFO) Recife, PE, \\ Brazil \\ 2 Federal Rural University of Pernambuco (UFRPE) Administration Department (DADM) Recife, PE, Brazil \\ ${ }^{3}$ Federal University of Pernambuco (UFPE) Informatics Center (CIn) Recife, PE, Brazil \\ * Corresponding author. Tel.: +55 081 3320-6491; email: marinho@deinfo.ufrpe.br \\ Manuscript submitted September 09, 2014; accepted December 24, 2014.
}

doi: 10.17706/jsw.10.3.288-303

\begin{abstract}
Nowadays organizations have the need to change constantly and the most effective way to do so is through projects. Not only being based on the management experience of various companies as well as on academic studies, it is also essential to verify an approach to project management in the organization and observe project uncertainties to manage them in a more suitable way. The aim of this paper is to present an Evidence-Based Software Engineering and based on that, to elaborate an approach to manage uncertainties in software projects.
\end{abstract}

Key words: Software project management, uncertainties in projects management, uncertainty in software projects.

\section{Introduction}

There is a great commercial competition that companies have to face nowadays, which demand fast decisions, optimum resource allocations and a clear focus definition. In a software development environment it is basically the same. Many types of project are proposed with different objectives in which need strategic management according to organizational goals.

Projects are fundamental for any company's success as well as activities which lead them to new products, services and business development. Successful projects lead to sales increase, costs reduction, quality improvement, client satisfaction, work environment, and other benefits. As a consequence, a large number of companies use project management as a key strategy to maintain competition and add value to their business.

Currently, software development organizations and specialized service organizations are organized as projects, which needs to be designed, structured, conduced, supervised, and most of all controlled. Indeed models and project management instrumentals have become fundamental to deal with software development complexity and challenges in software engineering.

Project are strategic for organizations, however there is still a large failure rate. When facing uncertainty, project managers do not to know how to act and it has been considered one of the drivers for these results [1]. According to Standish Group [2], 39\% of projects are realized as successful, finished on time and complied with requirements and budget defined; $43 \%$ are delivered with time, cost and requisites settings modified in relation to agreed; and, finally, $18 \%$ are canceled on delivery and never used.

The uncertainty and risk management should be considered complementary approaches, while risk management keeps on being an important tool, the project manager also needs strategies to manage uncertainties, or else, to deal with risk management areas that are unknown. 
In technical terms, risk can be defined as a "state of knowledge in which each alternative leads to a set of results and where the probability of occurrence is known by the decision maker". And uncertainty is "the state of knowledge in which each alternative leads to a set of results but the probability of occurrence of each outcome is unknown to the decision maker" [3].

Uncertainty can arise from deficiencies in a range of areas of knowledge, such as the contextual information on a project, our comprehension of underlying processes, explanations of past events and the velocity of change (or time). According to [4] uncertainty is much less susceptible to analysis; it is what is left behind when all the risks have been identified. Uncertainty represents a threat, but we cannot be sure what form it will take. If it was otherwise we would identify it as a risk. We may be able to see that there is a gap in our understanding but, unlike a risk, we do not perceive what it is that we do not know. Not until uncertainty manifests itself into a specific problem is the nature of the threat revealed and by then it may be too late to deal effectively with the consequences.

The use of uncertainty management within project management can be a determining factor in project success. One needs to clarify what can be done, decide what should be done, and ensure that management is carried out based on the prior identified uncertainties.

The uncertainty level is co-related with the existing quantity of information about the subject involved [5]. In Fig. 1 it is shown an uncertainty spectrum in which knowns when there is complete and enough information about what may happen and its impact on the project objectives, the certainty is total; known unknowns, if the information is partial, it is known that there is any probability for the event to happen and it is possible to evaluate the probable impact on the project objectives so it is risks; unknown unknowns, when there is a complete lack of knowledge of what is going to happen it is the uncertainty.

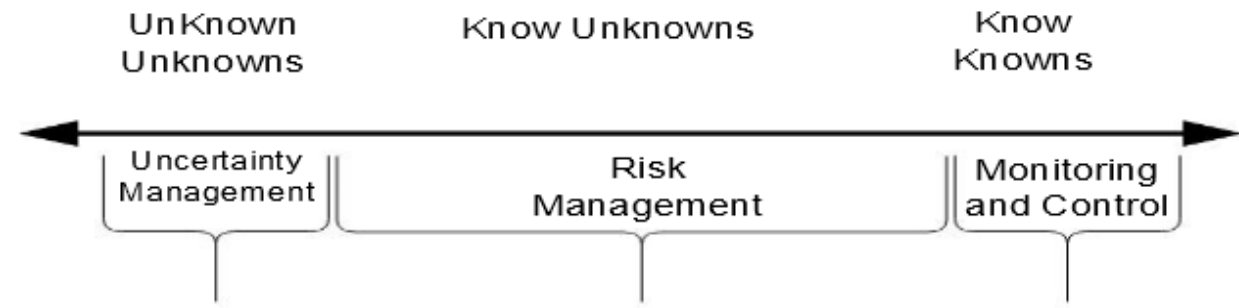

Fig. 1. Spectrum uncertainty - Adapted from [5].

The aim of this paper is to present an Evidence-Based Software Engineering and based on that an approach elaboration to manage uncertainties in software projects.

Besides the introductory section, this paper is structured as follows: Section 2 discusses about the methodology; Section 3 presents the informal study results; Section 4 presents the systematic review results; Section 5 the results for each systematic research question are presented and summarized; Section 6 presents an action research in a software development project; Section 7 offers an overview of a guide for uncertainty management in software projects and finally Section 8 contains the conclusion.

\section{Methodology}

The research method used in this work is based on the Experimental Software Engineering principles which is based in conducting primary and secondary studies in different investigation stages [6].

Evidence-based Software Engineering addresses to afford means by which the best valuable evidence from research can be combined with practical experience and human values in the decision-making process concerning to the development and software maintenance [7]. Indeed, evidence-based paradigm core is related to the systematic collection and analysis of the available data about a phenomenon for a more understandable and wider perspective than one can apprehend by means of a single study.

Kitchenham et al. [7] points out that Software Engineering can provide evidence-based instruments needed to 
help scholars and practitioners to embrace suitable technologies and avoid unappropriated ones, targeting the excellence in practices and procedures. Some authors advocate that Software Engineering researchers must consider the support of empirical studies to improve their decisions about which technologies to use [7]-[14].

The first step to start a scientific research is getting to know its main concepts and possible information sources. This step evaluates whether a baseline already exists with the main area concepts which could be used as a starting point for the research. An informal literature review was performed with the aim of identifying the basic concepts and the main research sources in the domain area.

Having identified and known a research area main concepts, the next activity is to obtain scientific evidence to allow the field maturity analysis of the area in question. According to Kitchenham [7], one of the research procedures such Based Software Engineering Evidence may be the implementation of a systematic literature review.

Besides the first two steps an action research was added to the design stage. According to Dick, [15] it has been common the use of action research in the evidence-based research paradigm context in these domains as means of connecting theory and practice, or else, academia and industry in both directions. in the following sub-section is about action research. In Fig. 2 it is shown the steps that guided this research.

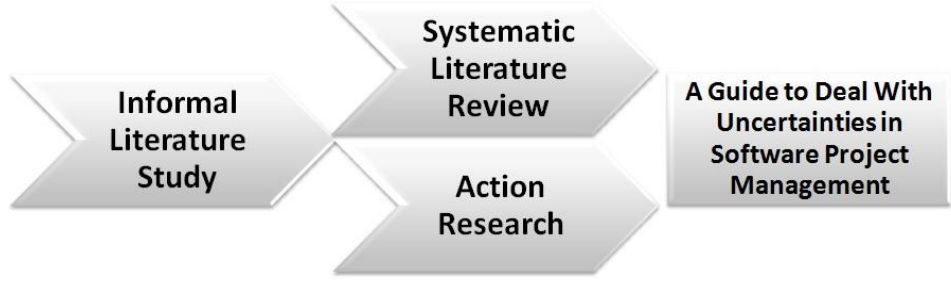

Fig. 2. Research methodology.

\subsection{Systematic Literature Review}

Systematic literature reviews are an approach to assess evidence in a systematic and transparent manner. In a conventional literature review, often, the research strategy and results evaluation criteria are usually hidden from the lector, which means that the procedures may be done in an irreproducibility manner, ad hoc and evidence that do not support the researcher's preferred hypothesis might be neglected. However, in a systematic literature review the study strategy and the assessment criteria must be explicit and all relevant evidence found during the inquiry are included in the analysis [7], [11], [13].

A systematic literature review "is a way of evaluating and interpreting all available research relating to a particular research question, topic area, or phenomenon of interest" [11]. Travassos [12] states that systematic reviews "provide the means to perform comprehensive literature review and not biased, giving their results have scientific value". In addition, Kitchenham [7] claim that systematic reviews address to present a fair assessment of a research topic using a reliable, accurate and auditable methodology.

\subsection{Action Research}

Most of the empiric research methods attempt to observe the world as it is currently; the action researchers aim to intervene in the studied situations with the explicit objective of improving the environment. the action research has its origin associated to the first interventionist practices done by Kurt Lewin [15] in the decade of 1940 in psychotherapy. Currently, it is used in several other areas as education, business and nursing. Its goal is to perform simultaneously research and action. The action is usually associated with some transformation in a community, organization or programme, while research is characterized by a greater transforming phenomenon understanding by the researcher (research community) or interested (client), or both [16].

A prerequisite for action research is making the problem owner disposed to contribute both to identify a problem and to engage in an effort to solve it. In action research, the problems owners become research collaborators. In some cases, the investigator and problem owner may be the same person. In addition, it is important for the action research that the researcher engage in a critical reflection process about their past, 
adding the researcher`s current and planned actions to identify how they actually helped (or not) to solve the problem [17].

Easterbrook et al. [17] argue that a lot of software engineering research is actually a disguised action research. Indeed, many key ideas in software engineering were originally developed by experiencing them in real development projects and reports on experiences. In this sense, Dittrich [18] describes the cooperative systems development as a ideal action research way for empirical software engineering. By adopting the action research structure more explicitly, it is likely that the design and evaluation of such research may become stricter.

\section{Informal Study Results}

The preliminary research identified four uncertainty sources [19], that can be considered by project managers. The sources works as a starting point for analysis, observation and identification of uncertainties in order to contribute to project success. In order to anticipate and sensor possible courses of project evolution, large corporations can better prepare project managers and senior leaders by accurately dimensionalizing the categories and characteristics of uncertainty.

\subsection{Technological Uncertainty}

The technological uncertainty is related to the maturity and amount of technology used in the project. Project technological uncertainty's level is not linear. It is subjective and dependent on how much the organization has access to it. It is, as a consequence, a measurement of the amount of existing new technology compared to mature technology available to use in the project [19].

In order to develop new products or functionality that demands high technology involved, it demands superior technology, even though a high technology risk is created. The use of very advanced technologies lead customers to expect an increase in performance and results, but according to the technologies to be developed in the project, these projects are much riskier than those who adopt known technologies [19].

\subsection{Market Uncertainty}

Market uncertainty is related to the level of consumer's knowledge, potential users, on a specific product and its usability and benefits. It represents "how new" are products to the market, the buyers and its users. The market uncertainty level indicates the external uncertainty and it influences in the project uncertainty goals as well. It also indicates how easy or complex is to introduce new products into market [19].

Different markets and consumers behave and think differently. In the same way, the project manager and other stakeholders should consider how their customers think, what their main problems are, how customer organizations work, and what kind of customer are they (i.e. government, business, or individual consumer), in order to decrease market uncertainties.

\subsection{Environment Uncertainty}

Environment Uncertainty indicates the external and internal organizational degree of uncertainty. Organizational theories stress that organizations must adapt to their environment if they wish to remain feasible [19].

First, environmental components and their specific dimensions must be identified. It is only by analyzing project's environmental characteristics that those uncertainties can be reduced. Such analysis facilitates the identification of environment types, contributing to different uncertainty degrees, as noticed by the individuals involved in the decision making [20].

\subsection{Socio-human Uncertainty}

The socio-human sources considers the relationships between people within an organization. In order to do so, it must consider religious and political issues, different values, personal experiences and cultural training. Any mentioned factor may affect both project performance and results. Project managers have to handle social differences and benefit from each team member's particularity and potential to promote project success [19]. 


\section{Systematic Review Results}

This section describes the analysis of the data extracted from our selected studies. The systematic review process adopted had four main stages: Data Search, Data Selection, Data Extraction, Quality Assessment and Data Synthesis.

\subsection{Research Questions}

The survey was conducted for the period being between 1994 and 2013. These are research questions which guided the systematic review:

- RQ 1: How is it possible to reduce the uncertainty level in software projects?

- RQ2: What practices (techniques or strategies) can help reduce the uncertainties in project management software?

\subsection{Data Search}

In the Data Search phase the searches were conducted in four sources:

- IEEEXplore Digital Library (httt://ieeexplore.ieee.org/);

- ACM Digital Library (http://portal.acm.org);

- Elsevier ScienceDirect (www.sciencedirect.com)

- Springer Link (http://link.springer.com);

The Table 1 shows the results obtained on each stage at systematic review process.

Table 1. Results Obtained on Each Stage at Systematic Review Process

\begin{tabular}{lll}
\hline \hline Stage & Procedures & Results \\
\hline Data Search & Search Engines & 2.933 papers \\
Data Selection & Phase 1 & 111 papers \\
Data Extraction and Quality Assessment & Phase 2 & 23 papers \\
Data Synthesis & Synthesis & 21 papers / 6 papers SnowBall / 103 \\
& & quotes \\
\hline \hline
\end{tabular}

Thus, were found the total of 3.044 papers in the period; at least 111 articles were identified and classified as duplicate articles. The search process was completed with a total of 2.933 articles ready for the next selection stage.

\subsection{Data Selection}

It was divided in phases: First: Title and Abstract analyses; and, Second: Introduction and the Conclusion analyses. In Phase 1, 111 articles were selected. In Phase 2, just 23 papers were selected for the extraction phase.

\subsection{Data Extraction and Quality Assessment}

In this step each researcher reads a full paper for the quotes extraction simultaneously with the paper quality assessment. Among the 23 read articles in the prior step, the researchers selected 21 papers to work. Two were considered not eligible because they did not answer the quality criteria. Further studies were identified by research technique snowball, 6 works that contributed to the discussion.

\subsection{Data Synthesis}

In this phase 103 quotas were analyzed, in which 30 answer the first research question; 73 the second.

\section{Systematic Review Discussion}

The results for research questions are presented. First RQ1 the evidences are presented about the possibility of reducing the uncertainties in software projects. Second RQ2 evidences on how the techniques or strategies 
that favor uncertainties reduction in project management.

\subsection{RQ1: How Can you Reduce the Uncertainty Level in Software Projects?}

To identify how to reduce the uncertainty in software projects, the following question was conducted. Out of the 27 works analyzed, 30 citations were identified, classified and grouped into five ways to deal with software projects uncertainties. Table 2 presents the five practices summarized and all evidence is properly referenced by the studies.

Table 2. Description Ways to Manage Uncertainties in Projects Identified by the Research

\begin{tabular}{|c|c|c|}
\hline What to do? & Description & Papers \\
\hline $\begin{array}{l}\text { Adopting techniques } \\
\text { and strategies to } \\
\text { facilitate the } \\
\text { uncertainty } \\
\text { reduction }\end{array}$ & $\begin{array}{l}\text { Although there are no easy answers or quick solutions, the uncertainty can be } \\
\text { "tamed", part of the answer lies in recognizing the nature of the problem and select } \\
\text { the right technique (or strategy) to work. Like any good craftsman, the project } \\
\text { manager must be in possession of a set of comprehensive tools for managing } \\
\text { uncertainty and - equally important - a good knowledge of the capabilities and } \\
\text { limitations of these tools. For different types of problems, the manager and the team } \\
\text { should have strategies, mindset and different paradigms. }\end{array}$ & $\begin{array}{l}\text { [1], } \\
{[21]-[27] .}\end{array}$ \\
\hline $\begin{array}{l}\text { Adapting } \\
\text { management style to } \\
\text { the type of projects }\end{array}$ & $\begin{array}{l}\text { The authors describe the importance of evaluating and analyzing the uncertainties } \\
\text { complexities of a project, and so adapt their management style to situation. It is also } \\
\text { addressed in some studies that projects fail because managers applied the wrong } \\
\text { management style to the project. }\end{array}$ & $\begin{array}{l}{[1],[19],[21],} \\
{[22],[28] .}\end{array}$ \\
\hline $\begin{array}{l}\text { Dealing with } \\
\text { uncertainty when } \\
\text { they happen }\end{array}$ & $\begin{array}{l}\text { Project managers can try to contain uncertainty at its font but they can hardly ever } \\
\text { have a hundred percent of success. Therefore, a project needs strength and should be } \\
\text { able to rapidly detect and respond to unexpected events. A project manager must } \\
\text { decide how best to cope with unexpected results. }\end{array}$ & $\begin{array}{l}{[1],[19],} \\
{[23],[25],} \\
{[26],[29]}\end{array}$ \\
\hline $\begin{array}{l}\text { Understand the } \\
\text { sources of } \\
\text { uncertainty to better } \\
\text { manage each type of } \\
\text { project }\end{array}$ & $\begin{array}{l}\text { Uncertainty can arise from deficiencies in various sources, such as contextual } \\
\text { information about the project, our understanding of underlying processes, past events } \\
\text { explanations and speed change. We may ask where these factors happen within a } \\
\text { project and what aspects of a project plan are particularly vulnerable to each } \\
\text { uncertainty type. }\end{array}$ & $\begin{array}{l}{[1],[19],} \\
{[21],[23],} \\
{[24],[30],} \\
{[31]}\end{array}$ \\
\hline $\begin{array}{l}\text { Identify } \\
\text { uncertainties in } \\
\text { order to turn it into } \\
\text { risk }\end{array}$ & $\begin{array}{l}\text { Strategies can be used to contain the uncertainties. These strategies can help you learn } \\
\text { more about the nature of uncertainty. Once an uncertainty is revealed, analytical } \\
\text { techniques, such as risk management can be used in project management. }\end{array}$ & {$[24],[30]$.} \\
\hline
\end{tabular}

\subsection{RQ2: What Practices Can Help Reduce the Uncertainties in Project Management Software?}

This question sought to identify practices to support the software projects management that help reduce the uncertainties in innovative projects. Out of 73 quotas extracted for that matter, 18 were found techniques or strategies for managing projects focusing on reducing uncertainties. These techniques and strategies are described in Table 3 with references of studies.

Table 3. Practices that Help Reduce the Uncertainties

\begin{tabular}{|c|c|c|}
\hline Practices & Description & Papers \\
\hline $\begin{array}{l}\text { Identifying the project } \\
\text { type to adopt appropriate } \\
\text { management }\end{array}$ & $\begin{array}{l}\text { To reduce a project's failure probability it is important to characterize it precisely, } \\
\text { learning then if there is an uncertainty related to their goals and solutions } \\
\text { adopting a management model that fits the project type. }\end{array}$ & $\begin{array}{l}{[1],[19],} \\
{[22],} \\
{[24]-[28],} \\
{[32]-[35] .}\end{array}$ \\
\hline $\begin{array}{l}\text { Managing the } \\
\text { expectations of } \\
\text { stakeholders so that they }\end{array}$ & $\begin{array}{l}\text { Innovative projects may create high expectations for clients. One needs to manage } \\
\text { those expectations, keeping them informed, aware of the project uncertainties and } \\
\text { create a bond of trust between project members and clients. }\end{array}$ & $\begin{array}{l}{[21],[22],} \\
{[24],[25],} \\
{[27],[29],}\end{array}$ \\
\hline
\end{tabular}


Ability to formulate qualitative measures of success

Identifying early warning signs to manage the uncertainties

Sensemaking

Management flexibility and ability to respond to changes

Managerial ability to perceive uncertainty and deal with them

Team willing to learn and develop new ideas in order to generate knowledge

The creation of flexible contracts

Building trust between team, management and customer

Verify information outside environment of the project

Understanding the sources of uncertainties

Project Managers must incorporate the investigation uncertainties in projects Learning method

Creativity techniques
Projects with low uncertainty can often be assessed through quantitative success measurement, such as time and cost, and tangible performance measurement related to their tangible final deliverables. Projects with high levels of uncertainty require different forms of performance evaluation that recognize the validity of different perspectives and worldviews.

Early identification of signs of a change can become a significant competitive advantage, because it can show an interruption in the current cycle, a break, beneficial or dangerous, for business. In the projects context, the early signs are of great importance, especially in innovative projects by having several associated uncertainties. The idea is to identify the cause of problems, and the solutions for each signal.

It is the process by which organizations and individuals work out uncertainties, ambiguities, changes and problem situations generating inventions and new situations that end up in actions that lead to problem solution and environmental stability.

The flexibility and ability to communicate the changes is fundamental. Complex and uncertain projects changes require greater flexibility and reflection. The project manager and the team performance should change as the profile and the uncertainty evolve.

The ability the project manager should have to take reasonable decisions to ensure there is necessary support to get everyone involved in the project; they must have personal ability, such as intuition and trial to perceive uncertainties.

Crisis management and continuous observation of threats and/or opportunities must be controlled by the team . When new information arises, everyone should be willing to learn and then formulate new solutions.

Creating flexible contracts for innovative projects help mitigating resistance to changes necessary for the project. In order to keep project stakeholders well informed, it is obviously important to have a flexible contract.

The relationship between clients, managers and teams is characterized by trust. Once it is conquered, helps facilitate the strategies change during the project.

Relevant actions to organizations or groups within the organization (suppliers, competitors, consumers, government, shareholders, etc) can affect the product, as well as doubts about the likelihood or nature of changes in the environment general condition (socio-cultural trends, demographic changes).

Project management can be conducted focusing on solving the project uncertainties; for doing so, it is necessary to understand where the uncertainties of projects can arise, ie, what the possible sources of uncertainty are. Understanding the sources we may be able to make the necessary changes as the project progresses.

Ongoing uncertainties investigation is important for projects members act in a proactive way and for the organization benefit strategically. The articles show that managerial knowledge aligned with research uncertainties may contribute to transformation of uncertainties in risk.

This is about experimentation and improvisation. The more we experience knowledge of a particular subject the more we reduce uncertainty. Improvisation itself can be a differentiator for innovative projects to deviate from uncertainties, leading to new goals.

Some articles suggest techniques to obtain knowledge such as: brainstorming
[21], [29], [35].

[36].

[1], [33].

[23], [25],

[27], [35].

[23], [25], [27], [35].

[1], [19],

[21], [25], [29], [37]-[39].

[19], [21]

[22], [25],

[29], [37],

[19], [21],

[22], [25],

[27], [36],

[21], [27].

[1], [19],

[21], [35], [41].

[1], [19], [41], [42].

[1], [19], [27], [39], [41].

[22], [27], [35].

[22], [27], 
Managers should facilitate communication within the organization

Managers should facilitate self-organization and the team adaptability The Collaborative Work
Some articles suggest that innovative projects with small teams and located in the same environment easily pass on the information received.

Managers need to encourage diversity of thought and interaction, breaking organizational and hierarchical structures. The team need to adapt to changes and to interact getting feedback with market and technology providers constantly.

The democratic management style is best appropriated; very tight control might lead an innovative project clutter and the project vision become an illusion. Collaborative working is essential in projects with many uncertainties.
[21], [22],

[25], [38].

[22], [35].

[1], [22], [36].

\section{An Action Research in a Software Development Project}

To develop and report the action research it was used the model described in [43] derived from the authors' experience in conducting different studies of action research in Software Engineering. Each step of action research will be presented.

\subsection{Diagnosis}

\subsubsection{Project context}

The 3D Seismic Project aimed to provide the study and development of a computer system based on a hybrid architecture with coprocessors implemented from FPGAs reconfigurable logic devices. The hardware and software modules design developed were tested on a reconfigurable platform. This system is able to solve problems with a high computational performance, being of interest to the Oil and Gas sector with performance comparable to multi-core technologies and GPUs or better. To further clarification of the issue, this process can take months to complete a certain region simulation, and at the same time, the competitiveness with oil discoveries in Brazil in the pre-salt layer, whose volume is estimated to be about 10 billion barrels of oil [44], requires new strategies implementation to accelerate the definition of favorable drilling points for its extraction. With the obtained results of this project Petrobras may achieve gains in performance if compared to general purpose CPUs. Such project was made for 21 people, with 1 coordinator, 1 consultant, 1 project manager, 1 chief scientist, 1 administrative secretary, 3 technical leaders, 8 computer engineers and 5 trainees. Besides UFPE Center for Informatics and Petrobras, the following organizations were involved: the University Foundation, responsible for administrative and legal support to the project and a third party, that we will call here XW, company responsible for a FPGA board development specified by the project team.

\subsubsection{Research subject}

According to the scenario previously presented, the investigation subject is defined as: a continuous uncertainty investigation related to the project; an evaluation of which practices (techniques and strategies) may contribute for the uncertainty reduction. Furthermore, an approach to manage the uncertainties in software projects.

\subsection{Research Action Planning}

In this section the planning phase is described and it starts with a intervention focus could be organized with the research objectives and expected results establishment. Finally, instruments, tools and techniques used in the research are presented.

\subsubsection{Action focus}

Action research was to goal establish practices that could manage the uncertainties in software projects and generate an approach to manage uncertainties. Our research question was: what practices may contribute to uncertainties management in the software projects? As expected results create an approach that can be adopted by software projects to reduce uncertainties. We point out that as action researchers agree with Thiollent [45], action research is not only a simple data collection but a research where researchers want to play 
an active role in the very reality of the observed facts, or else, throughout all the research process we operate actively in the project in order to support the uncertainties management.

\subsubsection{Operacional definitions}

Aligning with our focus, we established techniques for better conduction of action research; they were: semi-structured interviews, focus groups, follow-up meetings, retrospective meetings and follow-up activities. To support our activities we used tools such as: a specific directory in the project server to store all artifacts produced and used in the research, as well as electronic versions of publications, generated data sheet, partial reports and other documents.

\subsection{Actions}

The actions that were carried out during the research will be presented:

- Action 1 - Adapting Management Style to the Projects Type: As shown by HPCIn group, the adopted methods were not appropriated in the research and product development, so we decided to investigate how better adapt the group`s management style to their need in order to apply a better approach that helped in managing uncertainty.

- Action 2 - Project Planning: Due to technological uncertainties, the stakeholders were asked to attend meetings for a better project understanding. The brainstorming technique was used in four meetings attended by two Petrobras leaders, as well as the coordinator, consultant, project manager, chief scientist and 3 technical leaders. In addition, the project manager asked the chief scientist and 3 technical leaders a study in the area to verify the project feasibility. After that, we created a macro schedule (a Petrobras requirement) and adopted an agile planning, which raised all the user stories we learned so far (among them there were various activities of studies and prototyping). We applied the planning poker at that stage, except from the secretary, all staff was involved in the estimation process and we applied the rate of error percentage of the team (based on the history). adding the error percentage, the activities completion estimation was 18 months. However we still had uncertain components, such as: outsourcing the development of a FPGA board, the team suffered a little personnel turnover, we had restrictions imposed by the client in choosing the company that would develop the board, and as we were still in a university, we depended on the Administrative Foundation. Based on those uncertainties, we asked our client a deadline of 24 months.

- Action 3 - Creating Prototypes: For innovative projects there are uncertainties related to the goals and the solution. In most projects those aspects are both learned and defined as part of project execution. For R\&D projects the development cycle must contain research and prototype construction to converge on a goal by supporting a solution. Thus, we tried to perform prototyping since the beginning of the project.

- Action 4 - Continuous Early Warning Signs Investigation: We established an early signs investigation during the project. A constant observation was carried out during project implementation. We investigated which early signs arose during the project, we did a retrospective with the reported signs and performed a sensemaking to make a decision regarding the perceived signals every fortnight. The signs investigated in the project were listed by Nikander and Eloranta in [46] and Kappelman et al. [47].

- Action 5 - New Members Inclusion: Another problem we had was the constant change of employees and the impact on the insertion of a new team. So, before the project we adapted two spaces we had in the university campus to make it into a collaboration environment, a room for creating ideas. In addition, two team members left during the course of the project what led us to find a psychologist help to hold meetings with staff to define the professional profiles necessary for the group, and we developed a sociopsycho dramatic approach for selection and new team members inclusion. This procedure was adopted by the group and was assessed as positive by both team that had participated in the choice of new members and participants of the dynamics.

- Action 6 - Dealing with Uncertainty when They Happen: Project managers may try to contain uncertainty 
in its source, but never have one hundred percent success. Therefore, we try to be able to quickly detect and respond to unexpected events in our project. For unexpected results a project manager must then decide how best to deal with the uncertainty.

- Action 7 - Uncertainty Management Technique Adoption: We adopted several practices that contributed to a better project understanding and thus reduce uncertainties such as: managing stakehoders expectations, project success qualitative measures, early signs identification, flexible management and acting change, stimulus for team ideas generation, creativity techniques such as: brainstorming, feasibility study, collaborative work, continuous integration, multidisciplinary team.

\subsection{Evaluation and Analysis}

This section explores the study results, such as the learning design. Thus, these results will be exploited with the purpose of their organization and reflection on the knowledge gained from the actions.

After two years of project we completed the delivery as planned. The board we had ordered was not ready because the XW company had not completed its development in time, and because of that, our project was delivered in a lower performance board but with all algorithm working and processing seismic images properly. The customers received the project in time and said the goal was achieved and because of that other projects could be ordered.

We conducted a focus group with the team to assess the project completion and all the interventions made during the it. The team agreed that all practices embedded in the project contributed to its success, they praised the care taken in the research that was conducted with the project and that way contributed to: the staff acquire more knowledge, learn more about the project, learn how to behave when facing uncertainties and early signs, act when something unexpected happens and actually run the risk plan.

We interviewed the project coordinator, the consultant, the scientific leader and technical leaders, they were all in favour of interventions. The coordinator said in his interview that: "adopted practices ensured the project and the team success", yet, "At first, the uncertainties were plenty, but with this management style we could reduce uncertainty and achieve our goals". The scientific leader said: "It was like I was working from home, the environment, the people were united with one goal, of course there were differences, but all had cooperation in mind. The interventions were essential for doing so." One of the technical leaders said: "Despite all technological uncertainties, the XW not having delivered the board, we showed our customers that our team managed to reach the goal" The consultant said: "The elaborated practices here should be written for other people to use!".

\subsection{Reflections and Learning}

From the actions taken, we identified some practices that can help que uncertainty management, such as: Knowledge Strategies, Mindfulness culture, Multiple Perspective, Prototype, Differentiated Management Methodology, Stakeholder Management, Contractual Terms with Suppliers including Uncertainties, Early Identification, Iterative Identification, Comprehensive Identification, Emerging Identification, Risk Level, Historical/Past Review, Current Assessment, Creativity Techniques, Learning Strategies.

\section{A Guide to Deal with Uncertainties in Software Project Management}

The Fig. 3 shows a guide to manage uncertainties in an illustrative way. All activities are focused on the project manager and the team. in the characterization phase of the project the best methodology available is chosen for the project's context. in the figure it is represented as the rails of a train which may guide the project to the best way, but it is not enough. uncertainties are everywhere. the project manager must be aware about the uncertainty sources; furthermore, to verify which uncertainty source is the weakest. They need to pay attention on early warning signs that surrounds them and create a sensemaking. Thus, they may conventionally use the traditional risk management but unfortunately not all uncertainties may be noticed, so they must be prepared to some unexpected outcomes. When the uncertainties happen there are four ways to deal with them: suppressing, adapting, detouring or reorienting. Each phase of uncertainty management is going to be mentioned below. 


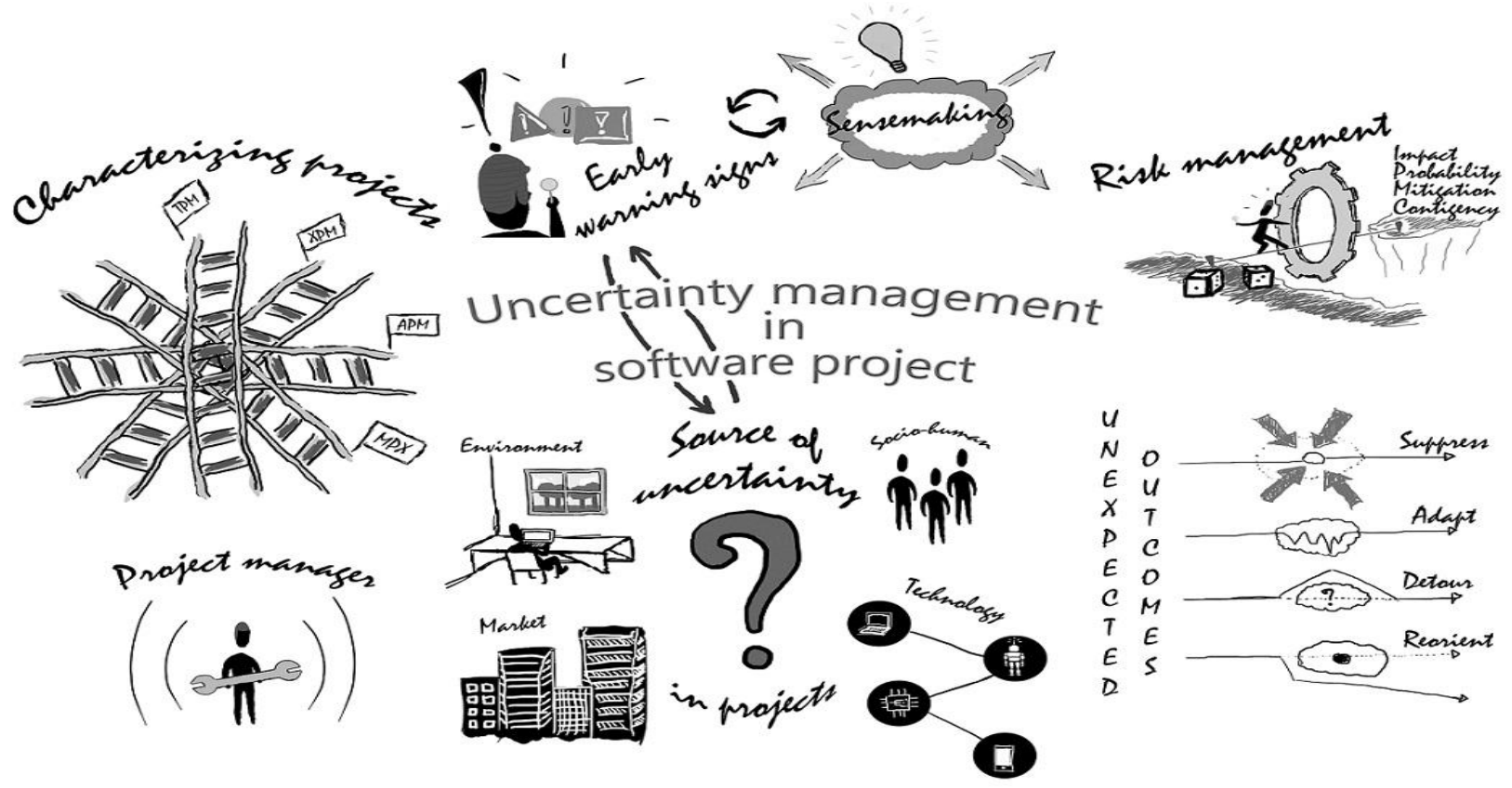

Fig. 3. Uncertainty management in software project.

\subsection{Characterizing Projects Phase}

In order to minimize the probabilities of failure in a project it is important to distinguish it correctly, in this way coming to identify whether or not an uncertainty exists in relation to aims and solutions, and adopting a model of management which is suitable for the kind of project.

The characteristics of projects can be depicted according to Fig. 4. The first dimension regards to the objective of the project which could find itself with a level of certainty or uncertainty. While, the second dimension refers to the solution, that is, whether there is certainty about the solution which should be detailed. In case we cross the dimensions, such as depicted in the Fig. 4, we might define a classification of which model can be applied to manage the project. It is important to highlight that the barrier between what is clear or not is purely conceptual, meaning that it cannot be defined quantitatively. As a consequence, it is an intuitive categorization to establish a better model for the project management.

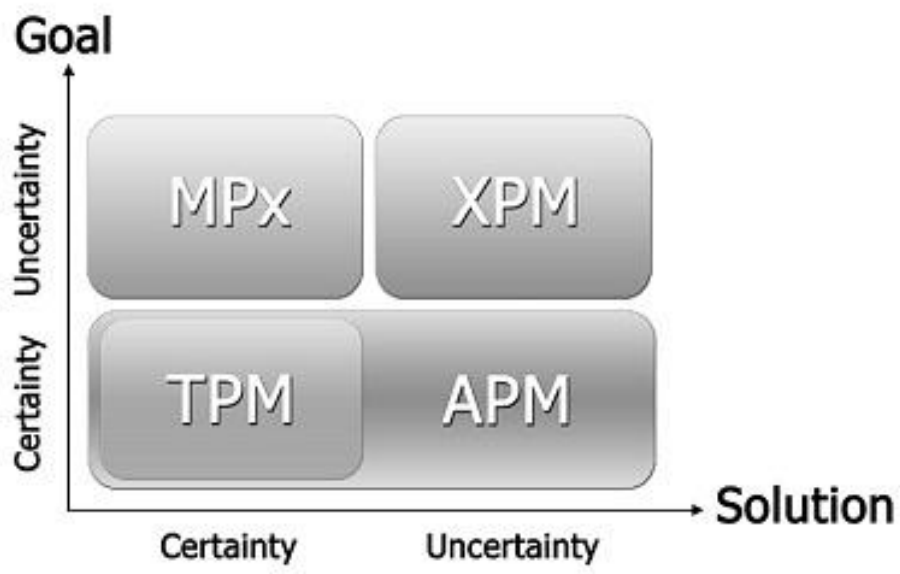

Fig. 4. Characterizing projects.

The projects can be classified as: 
- TPM: Tradicional Project Management;

- APM: Agile Project Management;

- XPM: Extreme Project Management;

- mPX: Emertxe Project Management;

The projects placed in the first quadrant of Fig. 4 can be executed by TPM or APM, being projects whose goals and solutions are clearly defined. In contrast, there are simple projects which were repeated several times in the past. There are well developed models or parts of them which are meaningful. They are projects which the organization is familiarized and the requisites are well known.

Placed in the second quadrant there are projects with clear objectives and part of the unknown solution - at once there is related risk. For these projects there is the indicated utilization of APM, since the requisites are not defined in a clear way adequately to elaborate the complete planning of a Project, as happens with TPM. For this kind of project the business value should be reliable enough to substantiate the adoption of a project with a high degree of uncertainty.

In the third quadrant, even though it appears to make no sense at first sight, there are important projects which consist of solutions looking for an objective. As an example we can point the project of the WalMart with RFID technology. "Can you find an application (objective of the project) of RFID technology (the solution) which has business value?" [48] They are broadly applied in innovation projects where we can characterize them as projects looking for an application (goal) of a technology (the solution) which possesses a business value.

In the fourth quadrant we have XPM projects. For this class of project there is high level of uncertainty in relation to the objectives and the solution. These are together apprehended and defined as part of the implementation of projects. They are generally RD projects which run the risk of not be finished. For these projects, the cycle of development can count on investigations and the prototypes building, all converging towards an objective which supports a solution.

\subsection{Source of Uncertanty Phase}

The uncertainty management starts with the understanding of the uncertainty sources. We may not always be aware of a specific uncertainty, but we can be alert to factors that may influence the success or failure of the project, it is important to understand the uncertainties sources.

\subsection{Early Warning Signs Phase}

Early signs can be verbally manifested, as contradictions in speech; non-verbally, such as messages tone and people`s mood; in writing, as indicators report, and events such as late delivery by a supplier. Through the early signs we could treat the first symptoms in an attempt to verify corrective actions for management. For the early signs anticipated recognition it is necessary their identification, as well as the comprehension of their meaning.

\subsection{Sensemaking Phase}

Sensemaking is the process by which organizations and individuals work uncertainties, ambiguities, changes and problem situations generating inventions and new situations that result in actions that lead to problem solution and environmental stability. The most important thing is that there is sense in the identified signal or else, it is plausible to those involved [35],[49].

\subsection{Risk Management Phase}

If the signs are early detected and a sense for them is created, strategies can be used to contain the uncertainties. These strategies can help to learn more about the uncertainty nature, for example, through problem formulation by representing or modeling future scenarios and prepare for them. Using discovery techniques such as the construction of a knowledge map. Once uncertainty is revealed, analytical techniques 
such as risk management can be used in project management [50].

\subsection{Unexpected Outcomes Phase}

Project managers may try to contain the uncertainty in its source but will never be a hundred percent successful. Therefore, a project needs strength and should be able to detect and respond quickly to unexpected events. For unexpected results a project manager must then decide how best to cope with uncertainty.

- Suppress: It consists of strategies to reduce the uncertainty impacts, allowing the project to return gradually to the original plan;

- Adapt: A certain uncertainty level is accepted, however, one must be prepared to act quickly and limit the major impacts of any unexpected event;

- Detour: If possible, we should deviate from all uncertainty areas; unfortunately, deviate from them is not always possible. Some are unavoidable or too costly; one should be careful not to exchange an uncertainty for another; we can only deviate from what we know;

- Reorient: A more drastic deviation should be used only as a last resort; We must look for a different set of objectives for the project; used in cases when uncertainty drives the design to total failure.

\section{Conclusion}

Various project management approaches do not consider the impact that the uncertainties have on the project management. The threats identified by uncertainty in day-to-day of a project are real and immediate and the stakes in a project are often high. The project manager faces a dilemma: decisions must be made now about future situations that are inherently uncertain. The use of uncertainty management in project management can be a determining factor in the success of the project.

It is not unpredictable that many projects fail, regardless of the business sector, software projects are notoriously disaster prone, not necessarily because of technological failure, but more often because of the uncertainties. This article introduced the construction of a uncertainty management guide designed by Software Engineering Based on Evidence. A primary study, a systematic literature review and an action research were conducted in a software project carried out in the IT Center of the Federal University of Pernambuco.

The results of this research contribute to software project management in two ways. First, the developing guide presents a way to manage uncertainties using the techniques and strategies that can support professionals and researchers in identifying relevant challenges and development of solutions for projects. Second, the search results provide the academic community a better understanding of the challenges of dealing with the uncertainties in project management and therefore, show gaps in the area that can be good opportunities for future research.

As future work, it is expected to refine the guide through qualitative analysis. The verification with third parties through surveys with project managers and scholars in the management area. Furthermore, it is expected to replicate the guide in different projects and compare the collected results.

\section{Acknowledgment}

Authors would like to thank CAPES for supporting the development of this work as well as the reviewers.

\section{References}

[1] Shenhar, A., \& Dvir, D. (2007). Reinventing Project Management: The Diamond Approach to Successful Growth and Innovation. Harvard Business Press.

[2] (2013). Standish group international. Retrieved August 2, 2013, from http://www. standishgroup.com

[3] Jauch, L., \& Kraft, K. (1986). Strategic management of uncertainty. Academy of Management Review, 777-790. 
[4] Cleden, D. (2009). Managing Project Uncertainty. Gower Publishing Company.

[5] Wideman, R. M. (1992). Project and program risk management: a guide to managing project risks and opportunities. Project Management Institute.

[6] Spínola, R. O. A., Neto, C. D., \& Travassos, G. H. (2008). Abordagem para desenvolver tecnologia de software com apoio de estudos secund'arios e prim'ario. Experimental Software Engineering Latin American.

[7] Kitchenham, B. A., Dyba, T., \& Jorgensen, M. (2004). Evidence-based software engineering. Proceedings of the 6th International Conference on Software Engineering (pp. 273-281).

[8] Dyba, T., Dingsoyr, T., \& Hanssen, G. K. (2007). Applying systematic reviews to diverse study types: An experience report. Proceedings of the ESEM 2007 First International Symposium on Empirical Software Engineering and Measurement (pp. 225-234).

[9] Keele, S. (2007). Guidelines for performing systematic literature reviews in software engineering. EBSE Technical Report EBSE-2007-01, Tech. Rep.

[10] Kitchenham, B. (2004). Procedures for Performing Systematic Reviews. Keele, UK, Keele University.

[11] Oates, B. J., \& Capper, G. (2009). Using systematic reviews and evidence-based software engineering with masters students. EASE, 9, 20-21.

[12] Travassos, G. H., Biolchini, J., \& Sistemáticas, H. D. R. (2007). Revisões sistemáticas aplicadas a engenharia de software. Proceedings of the XXI SBES-Brazilian Symposium on Software Engineering.

[13] Kitchenham, B., Brereton, O. P. D., Turner, B. M., J. Bailey, \& Linkman, S. (2009). Systematic literature reviews in software engineering-a systematic literature review. Information and Software Technology, (51)1, 7-15.

[14] Santos, R., Werner, C., Costa, H., \& Vasconcelos, S. (2011). Supporting software engineering education through a learning objects and experience reports repository. Proceedings of the 23nd International Conference on Software Engineering and Knowledge Engineering (pp. 272-275).

[15] Dick, B. (2004). Action research literature themes and trends. Action Research, 2(4), 425-444.

[16] Santos, P. S. M. D., \& Travassos, G. H. (2008). Colaboração entre academia e indústria: Oportunidades para utilização da pesquisa-açãoo em engenharia de software.

[17] Easterbrook, S., Singer, J., Storey, M., \& Damian, D. (2008). Selecting empirical methods for software engineering research. Guide to Advanced Empirical Software Engineering, 285-311.

[18] Dittrich, Y., Floyd, C., \& Klischewski, R. (2002). Social Thinking-Software Practice. Mit Press.

[19] Marinho, M., Sampaio, S., \& Moura, H. (2013). An approach related to uncertainty in software projects, Proceedings of the 2013 IEEE International Conference on Systems, Man, and Cybernetics (pp. 894-899).

[20] Duncan, R. (1972). Toward an operant model of organizational learning: Adaptation to environmental uncertainty. Administrative Science Quarterly, 17(3), 313-327.

[21] Meyer, A. D. C., Loch, H., \& Pich, M. T. (2002). From variation to chaos. MIT Sloan Management Review, 43, 60-67.

[22] Ren, Y., \& Yeo, K. (2005). Managing uncertainty in technology acquisition: the implications of complexity theory. Proceedings of the Conference on IEEE International, Engineering Management, (pp. 695-699).

[23] Romito, C., Probert, D., \& Farrukh, C. (2008). Technology evaluation under information inadequacy. Management of Engineering and Technology, 1672-1679.

[24] Loch, C. H., Solt, M. E., \& Bailey, E. M., Diagnosing unforeseeable uncertainty in a new venture. Journal of Product Innovation Management, 25(1), 28-46.

[25] Perminova, O., Gustafsson, M., \& Wikstr"om, K. (2012). Defining uncertainty in projects-a new perspective. International Journal of Project Management, 26(1), 73-79.

[26] Cleden, M. D., (2012). Managing Project Uncertainty. Gower Publishing, Ltd..

[27] Russo, R. D. F. S. M., Sbragia, R., \& Yu, A. S. O. (2013). Determining factors in the unforeseeable uncertainty management in innovation projects. Proceedings of the Technology Management in the IT-Driven Services (PICMET)(pp. 623-634). 
[28] Shenhar, A. J., \& Bonen, Z. (1997). The new taxonomy of systems: Toward an adaptive systems engineering framework. Proceedings of the IEEE Transactions on Systems, Man and Cybernetics, Part A: Systems and Humans (pp. 137-145).

[29] Wang, Q., \& Liu, J. (2006). Project uncertainty, management practice and project performance: An empirical analysis on customized information systems development projects. Proceedings of the 2006 IEEE International Engineering Management (pp. 341-345).

[30] Tatikonda, M. V., \& Rosenthal, S. R. (2000). Technology novelty, project complexity, and product development project execution success: A deeper look at task uncertainty in product innovation. Proceedings of the IEEE Transactions on Engineering Management (pp. 74-87).

[31] Ward, S., \& Chapman, C. (2003). Transforming project risk management into project uncertainty management. International Journal of Project Management (pp. 97-105).

[32] Shenhar, A. J., \& Dvir, D. (1995). Managing technology projects: a contingent exploratory approach. Proceedings of the Conference on Twenty-Eighth Hawaii International (pp. 494-503).

[33] Atkinson, R., Crawford, L. \& Ward, S. (2006). Fundamental uncertainties in projects and the scope of project management. International Journal of Project Management, (24)8, 687-698.

[34] Loch, C. H., DeMeyer, A., \& Pich, M. T. (2011). Managing the Unknown: A New Approach to Managing High Uncertainty and Risk in Projects. John Wiley \& Sons, 2011.

[35] Weick, K. E., \& Sutcliffe, K. M. (2011). Managing the Unexpected: Resilient Performance in an Age of Uncertainty. John Wiley \& Sons.

[36] Levy, M., \& Hazzan, 0. (2009). Knowledge management in practice: The case of agile software development. Proceedings of the ICSE Workshop on Cooperative and Human Aspects on Software Engineering (pp. 60-65).

[37] Jaafari, A. (2001). Management of risks, uncertainties and opportunities on projects: time for a fundamental shift, International Journal of Project Management, (19)2, 89-101.

[38] Little, T. (2005). Context-adaptive agility: managing complexity and uncertainty. Software, (22)3, 28-35.

[39] Chytka, T. M., Conway, B. A., \& Unal, R. (2006). An expert judgment approach for addressing uncertainty in high technology system design. Technology Management for the Global Future, 444-449.

[40] Wang, Y., \& Li, F. (2009). How does project managers' personality matter?: building the linkage between project managers' personality and the success of software development projects. Proceedings of the 24th ACM Sigplan Conference Companion on Object Oriented Programming Systems Languages and Applications (pp. 867-874).

[41] O'Connor, G. C., \& Rice, M. P. (2013). A comprehensive model of uncertainty associated with radical innovation. Journal of Product Innovation Management, (30)1, 2-18.

[42] MacCormack, A., \& Verganti, R. (2003). Managing the sources of uncertainty: Matching process and context in software development. Journal of Product Innovation Management, (20)3, 217-232.

[43] Santos, P. S. M. D., Travassos, G. H., \& M. V. Zelkowitz. Action research can swing the balance in experimental software engineering. Advances in Computers, 205-276.

[44] Statistics relating to petrobras. (2013). Retrieved January 22, 2013, from, http://www.petrobras.com. $\mathrm{br} / \mathrm{pt} /$ energia-e-tecnologia/fontes-de-energia/petroleo/presal/

[45] Thiollent, M. (2011). Metodologia da pesquisa-ac, ao," in Metodologia da pesquisa-ac, ao.

[46] Nikander, I. O., \& Eloranta, E. (2001). Project management by early warnings. International Journal of Project Management, (19)7, 385-399.

[47] Kappelman, L. A., McKeeman, R., \& Zhang, L. (2006). Early warning signs of it project failure: The dominant dozen. Information Systems Management, (23)4, 31-36.

[48] Wysocki, R. K. (2010). Adaptive Project Framework: Managing Complexity in the Face of Uncertainty. Addison-Wesley Professional.

[49] Weick, K. E. \& Sutcliffe, K. M. Managing the Unexpected. Jossey-Bass San Francisco.

[50] Institute, P. M. (2013). A Guide to the Project Management Body of Knowledge: PMBOK Guide. 


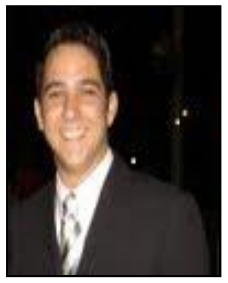

Marcelo Luiz Monteiro Marinho is currently an assistant professor at Department of Informatics (DEINFO) at Federal Rural University of Pernambuco in Brazil (UFRPE). He received his masters in computer science (CAPES Concept 6) at University Federal of Pernambuco (UFPE) and graduated in computer science. He had worked in the software field for 10 years in which 6 with software project management. His research interests include project management, software project management, strategic planning of information systems, software development process, IT management, software process and agile project.

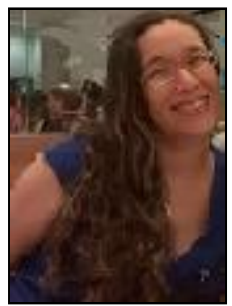

Suzana Cândido de Barros Sampaio has 17 years of experience on the software development industry, working for the last 9 years as a consultant in process improvement, agile methodology and project management. She is currently a $\mathrm{PhD}$ candidate at Informatics' Center at Federal University of Pernambuco (CIn-UFPE). Her research focuses on software project management where she investigates software project actuality. Also works as an assistant professor at Department of Informatics (DEINFO) at Federal Rural University of Pernambuco in Brazil (UFRPE). She holds a masters in computer science (CAPES Concept 6) at University Federal of Pernambuco (UFPE), on Software Development Productivity (2010) and graduated in computer science in 2000. Her research interests include project management, agile project management, process improvement and quality assurance

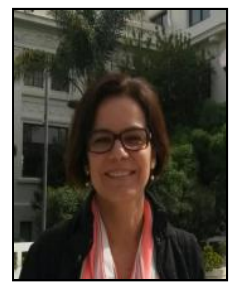

Telma Lúcia de Andrade Lima is lecturer at the Federal Rural University of Pernambuco (UFRPE), Brazil. She holds a doctorate in production engineering from Federal University of Pernambuco (UFPE), master in production engineering from UFPE and bachelor in mathematics from UFRPE, Brazil. She is currently acting as a lecturer, teaching Decision Support Systems and Knowledge Management, and as researcher. Her research interests include negotiation, partnerships, innovation in new technologies, entrepreneurship, startups and knowledge management

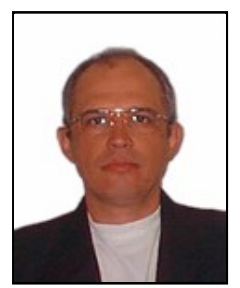

Hermano Perrelli de Moura is an associate professor and prorector for Planning and Finance, Federal University of Pernambuco (Recife, Brazil). He received his $\mathrm{PhD}$ in computing science from University of Glasgow, Scotland, in 1993. He received his MSc in computing science from Federal University of Pernambuco, Brazil, in 1989. He received his electronic engineer degree from Federal University of Pernambuco, Brazil in 1982. His research interests include management of software projects; software process improvement; strategic planning of information systems. 